\title{
Mapping Social Vulnerability to Air Pollution: A Case Study of the Yangtze River Delta Region, China
}

\author{
Yi Ge ${ }^{1, *}$, Haibo Zhang ${ }^{2, *}$, Wen Dou ${ }^{3}$, Wenfang Chen ${ }^{4}$, Ning Liu ${ }^{5}$, Yuan Wang ${ }^{1}$, Yulin Shi ${ }^{1}$ \\ and Wenxin Rao ${ }^{1}$
}

1 State Key Laboratory of Pollution Control \& Resource Reuse, School of the Environment, Nanjing University, Nanjing 210093, China; ywang@nju.edu.cn (Y.W.); yulinshilyn@163.com (Y.S.);

njuwxrao@outlook.com (W.R.)

2 School of Government, Center for Risk, Disaster \& Crisis Research, Nanjing University, Nanjing 210093, China

3 School of Transportation, Southeast University, Nanjing 210018, China; waynedou@gmail.com

4 State Key Laboratory of Severe Weather, Chinese Academy of Meteorological Science, Beijing 100081, China; wenfang_cams@163.com

5 School of Chemistry and Life Science, Jinling College, Nanjing University, Nanjing 210093, China; liuning@nju.edu.cn

* Correspondence: geyi@nju.edu.cn (Y.G.); zhb@nju.edu.cn (H.Z.); Tel.: +86-25-8968-0735 (H.Z.); Fax: +86-25-8968-0529 (Y.G.)

Academic Editor: Vincenzo Torretta

Received: 5 December 2016; Accepted: 10 January 2017; Published: 13 January 2017

\begin{abstract}
Many frequent and severe air pollution incidents have emerged across the vast parts of China recently. The identification of factors and mapping social vulnerability has become extremely necessary for environmental management and sustainable development. However, studies associating social vulnerability with air pollution remain sparse. With reference to research achievements of social vulnerability, this study made a new trial regarding social vulnerability assessment to air pollution. With the projection pursuit cluster (PPC) model, the top three factors contributing to social vulnerability index (SVI) were discovered and SVI and SVI dimensions (susceptibility, exposure, and adaptability) were evaluated. Results revealed that adaptability values are higher than susceptibility and exposure values. SVI is in a poor condition as, for the whole region, most values belong to the high-medium level. High SVI values mainly appear in the northern and the southern ends of study area. SVI in Shanghai is lower than in Jiangsu and Zhejiang provinces. On the scale of prefecture-level city, it can be found that the low-value centers of SVI always occurred in urban core areas. The spatial variation and inequality in social vulnerability provide policy-makers a scientific basis for air pollution prevention and sustainable management.
\end{abstract}

Keywords: social vulnerability index (SVI); air pollution; projection pursuit cluster model; Yangtze River Delta

\section{Introduction}

In recent years, a high number of environmental pollution disasters, such as air pollution, have emerged across vast parts of China [1-3]. Air pollution concentration in many regions of China has far exceeded the WHO's air quality guidelines [4-6], and twenty Chinese cities were listed among the world's thirty most polluted cities [7]. Cities in the Yangtze River Delta, Pearl River Delta, and Beijing-Tianjin-Hebei regions suffer from the worst air pollution, with $\mathrm{PM}_{2.5}$ concentration two to four times above the standards of the WHO guidelines [3]. In these regions, the average number of haze days has reached more than 100 days, and it even surpassed 200 days in several cities [8]. In January 2013, a thick haze had shrouded China's central and eastern provinces that covered 
a quarter of the whole country and affected a population of about 600 million [8]. In December 2015, Beijing issued its "red alert" for the first time, the highest level for heavy air pollution, and some particulate indices soared dozens of times above the daily maximum level recommended by the World Health Organization [9]. Air pollution poses a significant threat to human health, justice issues, and even cultural heritage [10-15]. In China, the mortality rate from respiratory diseases is greater than $17 \%$ and has become the third largest killer only after circulatory disease and cancer [7]. There is no doubt that air pollution disasters have become the most pressing challenge for development in China and urgent action should be taken for creating a sustainable future. Actually, a disaster is a result of an unsustainable development combined with an ambiguous cultural reaction to balance the natural, economic, and social setting [16]. Therefore, besides energy and industrial structure adjustments, vulnerability assessment is another effective solution to withstand adverse effects of a hostile environment [17], especially, the identification of social vulnerability to air pollution can provide a scientific support for a reasonable resource allocation and efficient risk management. It is valuable and crucial to understand the nature of social vulnerability and develop a proper method to measure social vulnerability in the environment context.

Considerable articles have established the genealogy of vulnerability research [18]. The initial scientific use of "vulnerability" has its roots in natural hazards research. In 1974, White first defined that "vulnerability is the degree to which a system, sub-system, or component is likely to experience harm due to exposure to a hazard, either a perturbation or stress" [19]. At that time, vulnerability works were mainly associated with the place-based exposure by physical scientists and engineers, which led to social aspects of vulnerability that were largely ignored [18]. In 1975, White and Haas advanced the idea that hazard research needed to take human factors, such as economic, social, and political aspects, into account because these factors also influenced vulnerability. During the late 1970s and early 1980s, the use of demographic data to assess social vulnerability came about as a paradigm shift in the standard interpretation of natural disasters [20]. It was really in the late 1990s that there began to emerge a growing community of researchers that sought to quantify and derive definitive methodologies for social vulnerability [21]. Research on vulnerability to date has stemmed from a variety of fields in the natural and social sciences, such as climate change, environmental degradation, development studies, food insecurity, poverty, and technological disasters [22-24]. Every field has defined the concept differently, manifest in a host of definitions and approaches [25]. However, it has been admitted that vulnerability, as a multidimensional concept, includes social, economic, and political structures, and an environmental setting [26-29] and can be classified into three types of vulnerabilities: biophysical vulnerability, social vulnerability, and a combination of the two [30].

Social vulnerability is the predisposition and inner state of human societies or individuals that can affect the way they experience natural hazards, climate change, or other dangerous incidences [31]. It includes the socio-economic status of groups of people, demographic traits, perceptions, and attitudinal differences towards people and places, social networks, access to capital and resources, physically weak individuals, cultural beliefs, access to basic infrastructure, and access to political power $[20,29]$. Social vulnerability is partially regarded as the product of social inequalities and "place inequalities" from the built environment $[25,29]$. Several major conceptual models have been proposed and can help us understand and analyze social vulnerability; for example, the Pressure and Release (PAR) framework [32], Hazards of Place (HOP) framework [27], Exposure-Sensitivity-Resilience framework [33], and Exposure-Sensitivity-Adaptive Capacity (ESA) framework [17]. Compared with biophysical vulnerability assessments, social vulnerability assessments are relatively ignored. Many social vulnerability studies use case study and qualitative assessments about the root causes of vulnerability to different hazards in various countries and world regions [34]. This is mainly due to the fact that there are more difficulties in quantifying social vulnerability [25]. Since the 1990s, a new methodology of aggregating the related indicators to produce a composite index of social vulnerability has been explored [35]. Currently, it has become the principal methodology adopted by most researchers in the field of social vulnerability studies [36]. 
This methodology provides a useful tool for identifying and monitoring social vulnerability over time and space, as well as a means for understanding the dynamic characteristics of human systems' underlying social vulnerability. However, how to aggregate indicators properly is still challenging [37]. Some researchers averaged component indicators while others assigned weights to various indicators. Cutter proposed a weighting scheme by examining spatial patterns of social vulnerability at the county level with principal components analysis (PCA) [29]. The index ultimately composited was called the Social Vulnerability Index and was firstly abbreviated to SoVI by Cutter. This aggregation method has been applied widely and become classic for social vulnerability assessment [38-42]. Other researchers have explored some innovative methods of aggregation. For example, Wei and Huang et al. assessed regional vulnerability to natural disasters in China with the method of data envelopment analysis (DEA) [43,44]. Fan et al. applied the method of analytic hierarchy process (AHP) to estimate social vulnerability to multiple hazards in China [45]. Additionally, with the AHP, Roy and Blaschke presented a grid-based method for quantifying vulnerability to floods in Bangladesh [46]. Rygel constructed a social vulnerability index for hurricane storm surges in a developed country with the Pareto ranking method [47]. Moreover, Ge explored the method of projection pursuit cluster (PPC) for quantifying social vulnerability to floods of the Yangtze River Delta in China [36].

The remainder of this paper is organized as follows: In Section 2, after conceptualizing social vulnerability in the context of air pollution, a method for assessing social vulnerability with projection pursuit cluster (PPC) model is proposed with a case study of the Yangtze River Delta Region in China. In Section 3, based on the results from PPC model, spatial variations of social vulnerability index (SVI) and SVI dimensions (susceptibility, exposure, and adaptability) are mapped and analyzed. Finally, the paper closed with conclusions and recommendations in Section 4.

\section{Materials and Methods}

The methodology used in this article is shown in Figure 1.

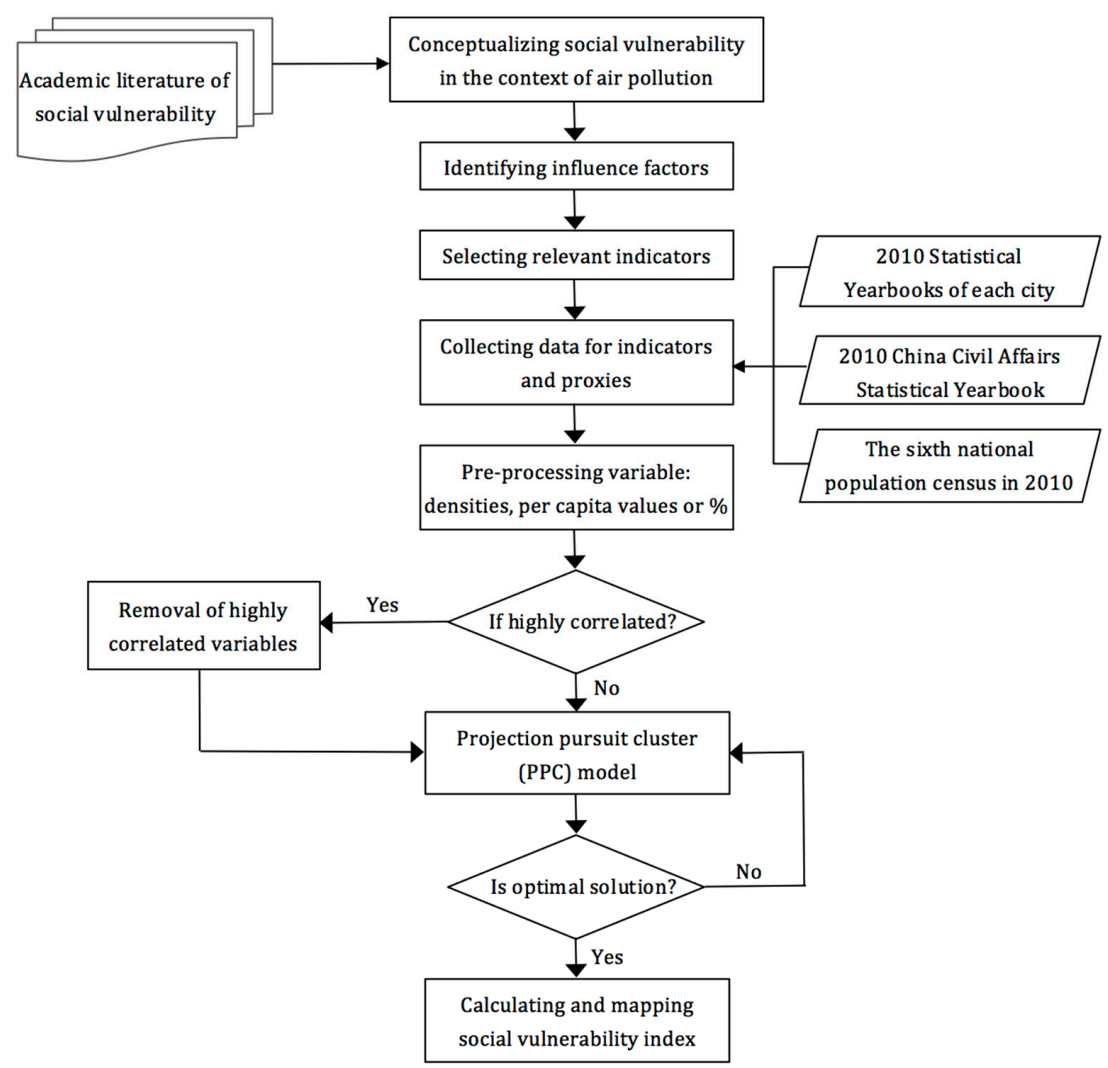

Figure 1. Methodology for assessing social vulnerability in the Yangtze River Delta. 
First of all, we conceptualized social vulnerability in the context of air pollution, referring to relevant studies of natural hazards (Figure 2). As we know, most attributes of a subject (e.g., people or region) fall into one of the three categories: environment, economy, and society. When subjects suffered from air pollution, these attributes would manifest in three forms of vulnerability: exposure, susceptibility, and adaptability. In the risk perspective, these three dimensions can be divided into biophysical and social vulnerabilities which interact with each other and produce the overall place vulnerability [29]. Place vulnerability interacts with air pollution to produce damage, such as disease and economic losses. Damage, in turn, can affect attributes of subjects and, furthermore, moderate or enhance vulnerability to air pollution. In this article, we only focus on the social vulnerability portion.

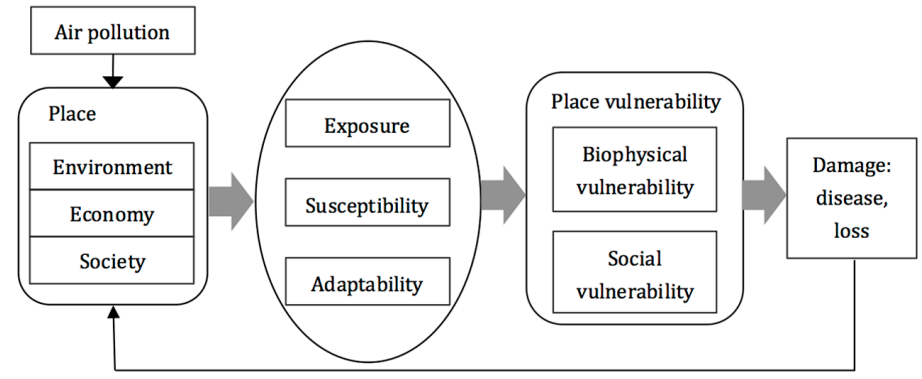

Figure 2. Conceptual framework of social vulnerability in the context of air pollution.

\subsection{Data}

Based on a wide range of academic literature of social vulnerability and social inequality to air pollution, major influencing factors of social vulnerability to air pollution were identified and relevant indicators were initially selected (see Table 1) [29,30,34,36,38,41,48-52].

Table 1. Factors and indicators of social vulnerability to air pollution.

\begin{tabular}{|c|c|c|}
\hline Factors & Indicator Names & Description \\
\hline Age & Children and Elderly & $\begin{array}{l}\text { Children and the elderly are especially sensitive to air pollution. Physiologic } \\
\text { immaturity and developmental changes account for children's susceptibility } \\
\text { to air pollutants. For older people, comorbidity, physical fragility and less } \\
\text { appropriate immune responses decrease their coping capacity. } \\
\text { Source: }[10,29,53-56] \text {. }\end{array}$ \\
\hline Gender & Female & $\begin{array}{l}\text { Women can have a more difficult time during recovery than men, often due to } \\
\text { lower wages, and family care responsibilities. Source: }[27,29,32] \text {. }\end{array}$ \\
\hline Ethnicity & Ethnicity & $\begin{array}{l}\text { Imposes language and cultural barriers that affect the ability to seek, find or } \\
\text { understand warning information and access recovery information. } \\
\text { Source: [29]. }\end{array}$ \\
\hline Education & Illiterate and Educated & $\begin{array}{l}\text { People highly educated are more likely to have better employment prospects, } \\
\text { which results in better economic conditions and more resources to take } \\
\text { precaution against air pollution. Source: }[29,57-59] \text {. }\end{array}$ \\
\hline $\begin{array}{l}\text { Individual } \\
\text { economic status }\end{array}$ & Unemployed;Poor & $\begin{array}{l}\text { Low-income individuals often exposure to hazardous pollution environment } \\
\text { or can't take enough actions to protect themselves against air pollution. } \\
\text { Source: }[2,60-65] \text {. }\end{array}$ \\
\hline $\begin{array}{l}\text { Population } \\
\text { exposure }\end{array}$ & $\begin{array}{l}\text { Urban resident; Employees in } \\
\text { 2nd industry, mining, } \\
\text { manufactory and } \\
\text { construction; GDP in } \\
\text { secondary sector; } \\
\text { Population density }\end{array}$ & $\begin{array}{l}\text { Urban residents expose to severer air pollution for ambient heavy traffic. } \\
\text { High-exposure occupations lead to high health risk for potential cumulative } \\
\text { effects in air pollution. The boom and bust economy of secondary sector may } \\
\text { create more high-exposure occupation opportunities. Population density } \\
\text { illustrates discrepancy of average exposure among regions. } \\
\text { Source: }[2,17,51,59,66] \text {. }\end{array}$ \\
\hline Regional resource & GDP; Green space coverage & $\begin{array}{l}\text { "GDP" and "Green space coverage" demonstrate potential resources } \\
\text { available for absorbing, reducing the adverse impact and recovering from } \\
\text { losses more quickly. Source: }[17,25,29,57] \text {. }\end{array}$ \\
\hline $\begin{array}{l}\text { Medical and } \\
\text { management } \\
\text { services }\end{array}$ & $\begin{array}{l}\text { Beds and Physicians in } \\
\text { hospital; Employees in } \\
\text { management sector }\end{array}$ & $\begin{array}{l}\text { Public medical services can help for recovery and mitigation. Employees in } \\
\text { the sectors of management can reflect the capacity of environmental } \\
\text { governance. Source: }[25,29,59] \text {. }\end{array}$ \\
\hline
\end{tabular}


Data in this article come from the sixth national population census in 2010, 2010 statistical yearbooks of each city published by the cities' Statistical Bureaus, as well as the 2010 China Civil Affairs Statistical Yearbook. The data of "green space coverage" comes from "Lake-Watershed Science Data Center, National Earth System Science Data Sharing Infrastructure, National Science and Technology Infrastructure of China"(http://lake.geodata.cn). Both the developing country context and data availability are taken into account and, ultimately, 20 indicators for 139 counties in our study area were collected. All indicators were identified with three dimensions of social vulnerability: susceptibility, exposure, and adaptability. The indicators belonging to "susceptibility" or "exposure" tend to increase social vulnerability, while those for "adaptability" tend to decrease social vulnerability. With these indicators, a composite score of social vulnerability can be evaluated and be named as social vulnerability index (SVI). Table 2 lists the datasets in detail. In Table 2, " + " represents a positive impact to SVI and indicates the indicator will increase social vulnerability. Similarly, "-" represents a negative impact to SVI and illustrates the indicator will decrease social vulnerability. Before the calculation, our data were normalized as percentages, per capita values, or density functions. A test for correlation analysis was also made in order to avoid high correlations among indicators, and the indicator "MANUFACT" was removed because of high correlation with the indicator "SECWORKER". Therefore, 19 indicators were actually selected for assessing the social vulnerability index.

Table 2. Detailed description of indicators for assessing social vulnerability index (SVI).

\begin{tabular}{|c|c|c|c|c|c|}
\hline No. & Indicator & Name & Description & $\begin{array}{c}\text { Dimension of } \\
\text { SVI }\end{array}$ & $\begin{array}{l}\text { Impact to } \\
\text { SVI }\end{array}$ \\
\hline 1 & Children & CHILD & Percentage of population under 14 years old & Susceptibility & + \\
\hline 2 & Elderly & ELD & Percentage of population over 65 years old & Susceptibility & + \\
\hline 3 & Female & FEMALE & Percentage of female & Susceptibility & + \\
\hline 4 & Ethnicity & ETHNICITY & Percentage of Ethnicity & Susceptibility & + \\
\hline 5 & Illiterate & ILLITERATE & $\begin{array}{l}\text { Percentage of illiterates among those } \\
\text { aged } 15 \text { and over }\end{array}$ & Susceptibility & + \\
\hline 6 & Poor & POOR & $\begin{array}{l}\text { Percentage of recipients of } \\
\text { subsistence allowances }\end{array}$ & Susceptibility & + \\
\hline 7 & Unemployed & UNEMPLOY & Percentage of unemployed & Susceptibility & + \\
\hline 8 & Population density & POPDENSITY & Population density & Exposure & + \\
\hline 9 & Urban resident & URBAN & Percentage of urban residents & Exposure & + \\
\hline 10 & $\begin{array}{l}\text { Employees in 2nd } \\
\text { industry }\end{array}$ & SECWORKER & Percentage of employed in secondary industry & Exposure & + \\
\hline 11 & $\begin{array}{l}\text { Employees } \\
\text { in mining }\end{array}$ & MINING & Percentage of employed in mining & Exposure & + \\
\hline 12 & $\begin{array}{l}\text { Employees } \\
\text { in manufactory }\end{array}$ & MANUFACT & Percentage of employed in manufactory & Exposure & + \\
\hline 13 & $\begin{array}{l}\text { Employees } \\
\text { in construction }\end{array}$ & CONSTRUCT & Percentage of employed in construction & Exposure & + \\
\hline 14 & $\begin{array}{l}\text { GDP in secondary } \\
\text { sector }\end{array}$ & INDUSTRY & Percentage of GDP in secondary sector & Exposure & + \\
\hline 15 & GDP & P_GDP & Gross domestic product per capita & Adaptability & - \\
\hline 16 & Educated & EDUCATE & Percentage higher education graduates & Adaptability & - \\
\hline 17 & Beds in hospital & HOSBED & Number of beds in hospital per 1000 people & Adaptability & - \\
\hline 18 & $\begin{array}{l}\text { Physicians in } \\
\text { hospital }\end{array}$ & HOSPHY & $\begin{array}{l}\text { Number of physicians in hospital } \\
\text { per } 1000 \text { people }\end{array}$ & Adaptability & - \\
\hline 19 & $\begin{array}{l}\text { Employees in } \\
\text { management sector }\end{array}$ & ENWORKER & $\begin{array}{l}\text { Percentage employees in the sectors of water } \\
\text { conservancy, environment and } \\
\text { public management }\end{array}$ & Adaptability & - \\
\hline 20 & $\begin{array}{l}\text { Green space } \\
\text { coverage }\end{array}$ & GREEN & Ratio of open green space coverage & Adaptability & - \\
\hline
\end{tabular}




\subsection{Case Study: The Yangtze River Delta Region}

This study focused on the Yangtze River Delta region located in the easternmost part of China, a metropolitan area with intensely developed and densely populated coastal frontages (Figure 3). It includes a total of 16 cities in this article, eight cities in the south of Jiangsu Province (Nanjing, Changzhou, Nantong, Suzhou, Taizhou, Wuxi, Yangzhou, and Zhenjiang), seven cities in the north and east of Zhejiang Province (Hangzhou, Huzhou, Jiaxing, Ningbo, Shaoxing, Taizhou, and Zhoushan), and Shanghai Municipality. According to the Constitution of China, Shanghai is a provincial-level municipality, and the others are prefectural-level cities. These sixteen cities govern 139 county-level districts, including city districts, counties, and county-level cities.

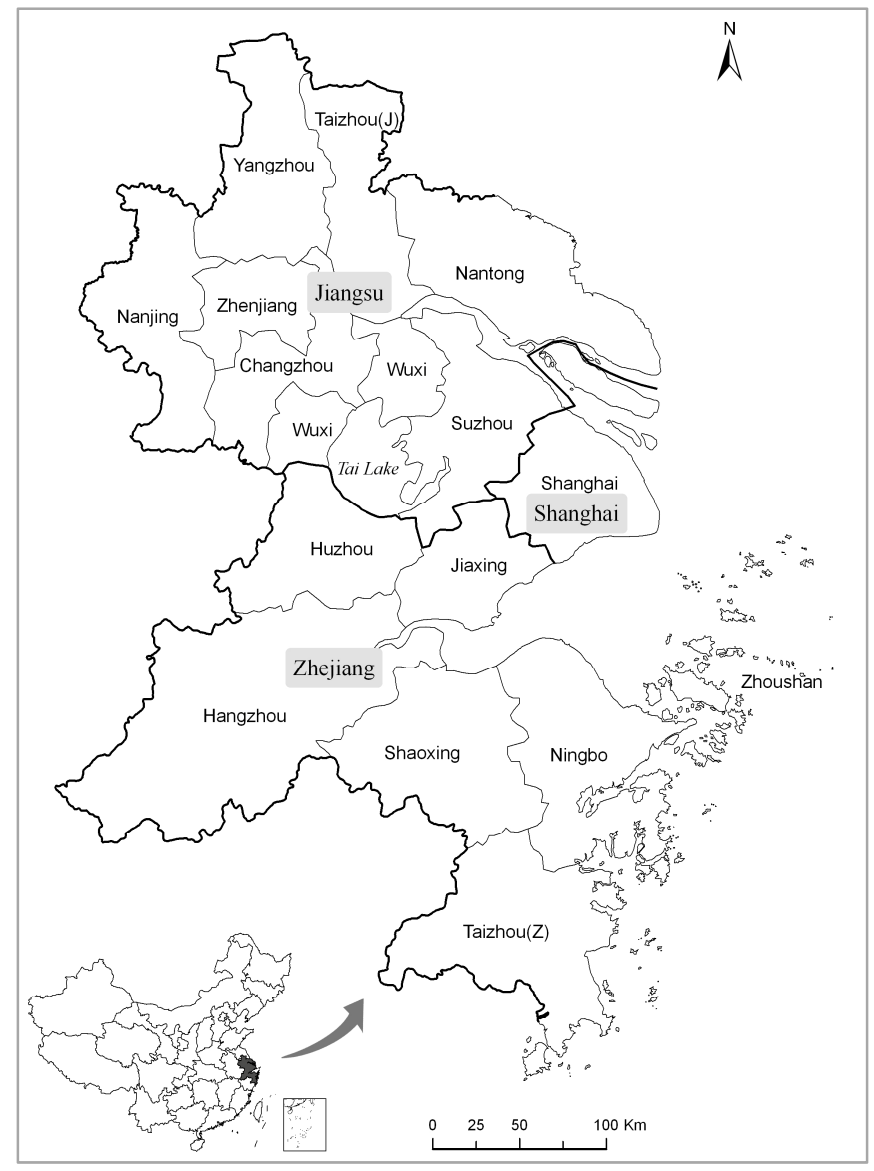

Figure 3. The Yangtze River Delta, China: location and cities.

The Yangtze River Delta (YRD) region covers an area of 180,935 $\mathrm{km}^{2}$ and had a population of 81 million in 2010. Accounting for 1\% of China's land area and $7.6 \%$ of its population, this region creates $17.6 \%$ of the country's GDP, produces $37.6 \%$ of its exports (by value), and attracts $41.8 \%$ of transnational investment in 2010. In terms of economy, technology, and culture, the delta region is one of the most developed and wealthiest in China. However, with rapid economic development and high-energy consumption, YRD has been suffering air pollution problems in the past three decades [67]. Air pollutant emissions are increasing steadily, regional visibility is decreasing, and ozone concentrations are increasing [68], all of which deteriorate the regional environment and pose high potential health risks to local residents. Hence, YRD is selected for assessing social vulnerability to air pollution in China. 


\subsection{Research Method: The Projection Pursuit Cluster (PPC) Model}

The projection pursuit cluster (PPC) model, a natural approach for data reduction, is used in this study to weigh the indicators and aggregate to SVI. Projection pursuit (PP) is a technique for seeking out a linear projection of multivariate data onto a lower dimensional space (especially one dimension) by means of optimization of the index of "interestingness", defined as a projection index [69]. Projection pursuit uses a projection index computed on a projected density to measure the interestingness of the current projection. Then it employs a numerical optimizer to move the projection direction to a more interesting position [70]. The index of interestingness has been designed purposely to reveal clustering characteristics hidden in the multivariate high-dimensional data. The PP technique can more clearly group data, exclude the interference of outliers, and solve the nonlinear problems by searching for nonlinear structures in the linear projection. The detailed procedure is as follows.

- Step 1: Normalize the values of proxy indicators

In this study, the dataset for estimating SVI is $\left\{x^{*}(i, j) \mid i=1,2, \ldots, n ; j=1,2, \ldots, p\right\}$, where $x^{*}(i, j)$ represents the value of the $i$ th observation with the $j$ th indicators. $n$ and $p$ are the number of observations and indicators, respectively. Here, $n=139$ and $p=19$. Different normalization formulas are used based on an indicator's influence on SVI. For indicators that increase SVI, the normalized variable value $x(i, j)$ is:

$$
x(i, j)=\left[x^{*}(i, j)-x_{\min }(j)\right] /\left[x_{\max }(j)-x_{\min }(j)\right]
$$

For indicators that decrease SVI,

$$
x(i, j)=\left[x_{\max }(j)-x^{*}(i, j)\right] /\left[x_{\max }(j)-x_{\min }(j)\right]
$$

- $\quad$ Step 2: Develop the index function $Q(a)$

The dataset of $\{x(i, j) \mid i=1,2, \ldots, n ; j=1,2, \ldots, p\}$ is converted into a one-dimensional projection value $z(i)$ :

$$
z(i)=\sum_{j=1}^{p} a(j) \times x(i, j), i=1,2,3, \ldots, n
$$

where $a(j)$ is a $p$-dimensional unit vector corresponding to projection direction, $a(j) \in[-1,1]$, and $\sum_{j=1}^{p} a(j)^{2}=1$. The projection value dataset varies with the projection direction $a(j)$. Different projection directions reveal different features of data structure and the optimal projection direction is the direction exposing the most interesting structure of high-dimensional data. In the one-dimensional scatter diagram, the most interesting projection corresponds to the view where there is the greatest difference among observations from other classes and the least difference in the same class. Thus, the index function can be depicted as follows:

$$
\begin{gathered}
Q(a)=S_{z} D_{z} \\
S_{z}=\sqrt{\sum_{i=1}^{n} \frac{(z(i)-E(z))^{2}}{n-1}} \\
D_{z}=\sum_{i=1}^{n} \sum_{j=1}^{n}(R-r(i, j)) \times u(R-r(i, j))
\end{gathered}
$$

where $S_{z}$ is the standard deviation of $z(i) ; D_{z}$ is the local density of $z(i) ; E(z)$ is the mean of $z(i) ; R$ is the local density radius of the window. In this study, it is $0.1 S_{z} ; r(i, j)$ is the distance between the samples: $r(i, j)=|z(i)-z(j)| ; u(t)$ is the unit step function: $u(t)=1$, if $r(i, j)<R$ or $u(t)=0$, if $r(i, j) \geq R$. 
- Step 3: Find the optimal projection by maximizing the index function

$$
\left\{\begin{array}{l}
\operatorname{Max} Q(a)=S_{z} D_{z} \\
\text { s.t. } \sum_{j=1}^{p} a^{2}(j)=1
\end{array}\right.
$$

The program for a real-coded genetic algorithm implemented in PYTHON is applied to calculate $a^{*}(j)$ of the best projection direction. The values of $a(j)$ in $p$-dimensions in Equation (3) corresponds to the weights of the indicators. Since $a^{*}(j)$ is the unit vector corresponding to the optimal direction that exposes the most interesting structure of 19 indicators, it can be thought as the suitable weights of social vulnerability indicators.

- Step 4: Calculate and classify social vulnerability index

When $a^{*}(i)$ has been calculated, the aggregated value $\left(Z^{*}(i)\right)$ taken as the social vulnerability index can be obtained according to Equation (3). Thus, nineteen indicators for assessing social vulnerability are compressed into one dimension without any loss of potentially useful information.

\section{Results and Discussion}

Results about weighting values of all indicators are shown in Table 3. Table 3 indicates that the maximum of weighting values is 0.416 and the minimum is 0.024 , which means the indicator of "educated" contributes most to SVI while "urban resident" affects SVI least. The top three indicators influencing on SVI are "educated", "physicians in hospital" and "employees in management sector", and all of them are above 0.3 . The next group $(0.255<$ value $<0.3)$ is composed of five indicators: "children", "employees in management sector", "beds in hospital", "employees in mining", and "GDP in secondary sector". These eight indicators make up $68.3 \%$ of the SVI and four of them belong to the dimension of "adaptability", three of them belong to "exposure", and only one belongs to "susceptibility". Which means that in the YRD region, the dimension of "adaptability" has more effect on the SVI value.

Table 3. Weighting values for SVI to air pollution.

\begin{tabular}{cccccc}
\hline No. & Indicators & $\begin{array}{c}\text { Weighting } \\
\text { Values }\end{array}$ & No. & Indicators & $\begin{array}{c}\text { Weighting } \\
\text { Values }\end{array}$ \\
\hline 1 & Children & 0.297 & 11 & Employees in mining & 0.274 \\
2 & Elderly & 0.120 & 12 & Employees in construction & 0.166 \\
3 & Female & 0.142 & 13 & GDP in secondary sector & 0.255 \\
4 & Ethnicity & 0.082 & 14 & GDP & 0.188 \\
5 & Illiterate & 0.245 & 15 & Educated & 0.416 \\
6 & Poor & 0.063 & 16 & Beds in hospital & 0.283 \\
7 & Unemployed & 0.040 & 17 & Physicians in hospital & 0.365 \\
8 & Population density & 0.060 & 18 & Employees in management sector & 0.355 \\
9 & Urban resident & 0.024 & 19 & Green space coverage & 0.044 \\
10 & Employees in 2nd industry & 0.288 & & & \\
\hline
\end{tabular}

With the weight of each indicator, we evaluated the values of SVI dimensions (susceptibility, exposure, and adaptability) in the YRD region (Figure 4). For 139 counties, the adaptability values are all higher than susceptibility and exposure values. Hence, improving adaptability of the YRD region will be an effective measure for reducing social vulnerability to air pollution. Spatial patterns of susceptibility, exposure, and adaptability are mapped as shown in Figure 5. 


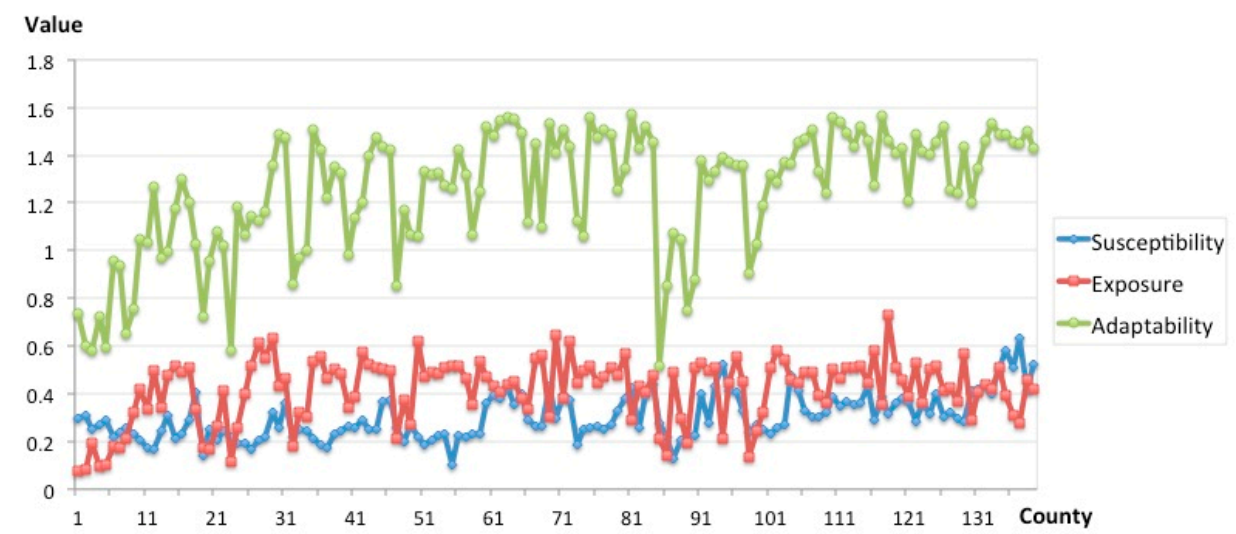

Figure 4. Changes of SVI dimensions: susceptibility, exposure, and adaptability.
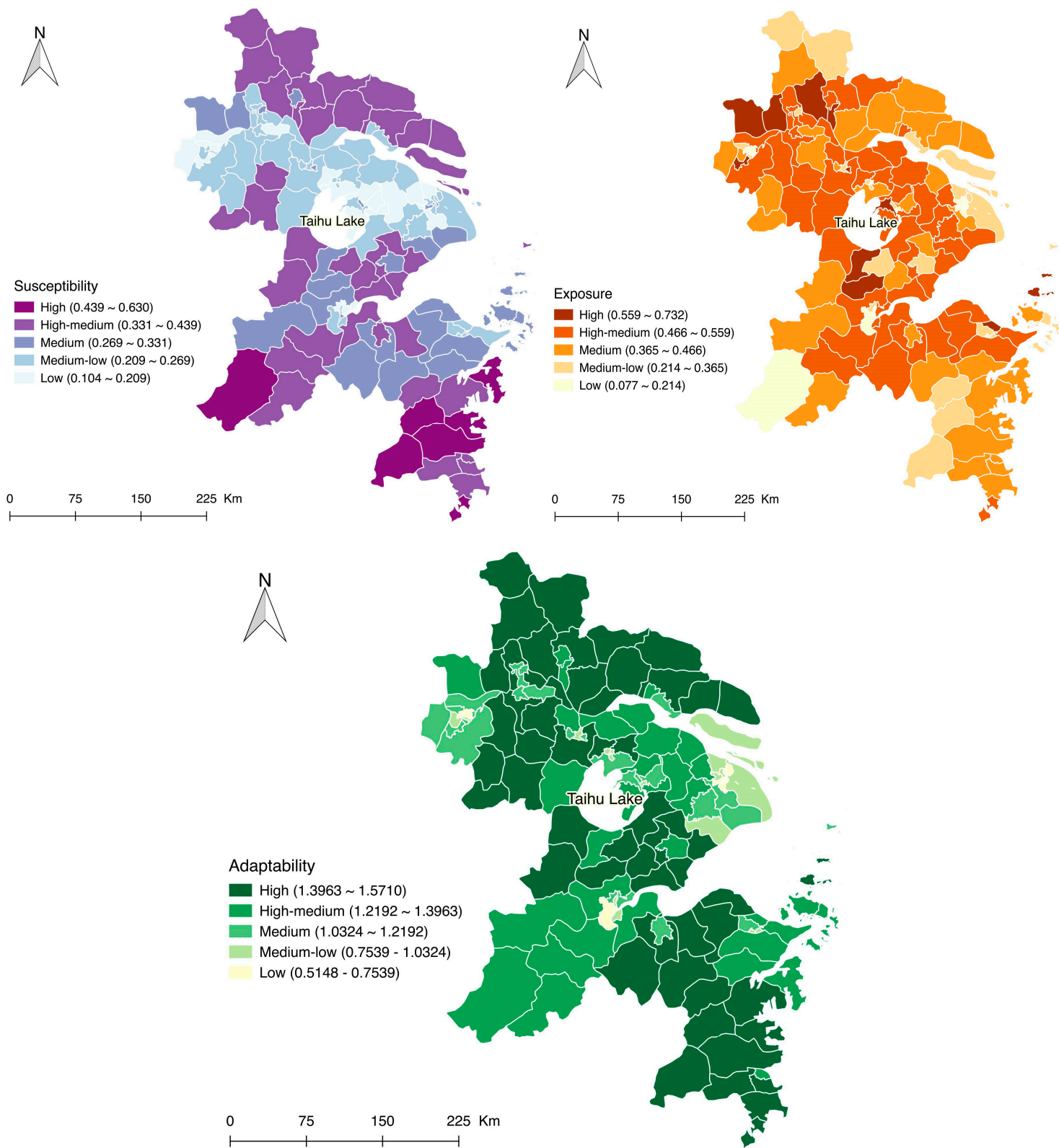

Figure 5. Spatial pattern of SVI dimension: susceptibility, exposure, and adaptability. 
These maps address significant spatial clustering and variability in each SVI dimension (Figure 5). With regard to the YRD region, counties in the southern and northern ends tend to be highly susceptible, have medium exposure, but are highly adaptable, coinciding with a lower level of local economic development, but a relatively adequate resource supply for their city size. Counties around the periphery of Taihu Lake are less susceptible, more adaptable, but face greater exposure, since this area has the advantage in economic development and social services, while population exposure and urban sprawl are among the most significant and widespread in the nation. As for counties in the metropolitan area of Shanghai, they are less susceptible, with less or medium exposure, but show less or medium adaptability. This suggests that local infrastructure and social services cannot keep pace with the rapid urban expansion, as even considerable development has been witnessed in Shanghai.

SVI values of all counties were evaluated and are displayed on Figure 6 and Table 4. It can be seen that there is an evident discrepancy among the three provincial units in the YRD region. SVI in Shanghai is generally lower than the other two: the average and maximum are both less than others. In Jiangsu Province, though the maximum is greater than Shanghai, the minimum is the least one. As for Zhejiang Province, the overall condition of SVI is not good: average, minimum, and maximum are all larger than the others.

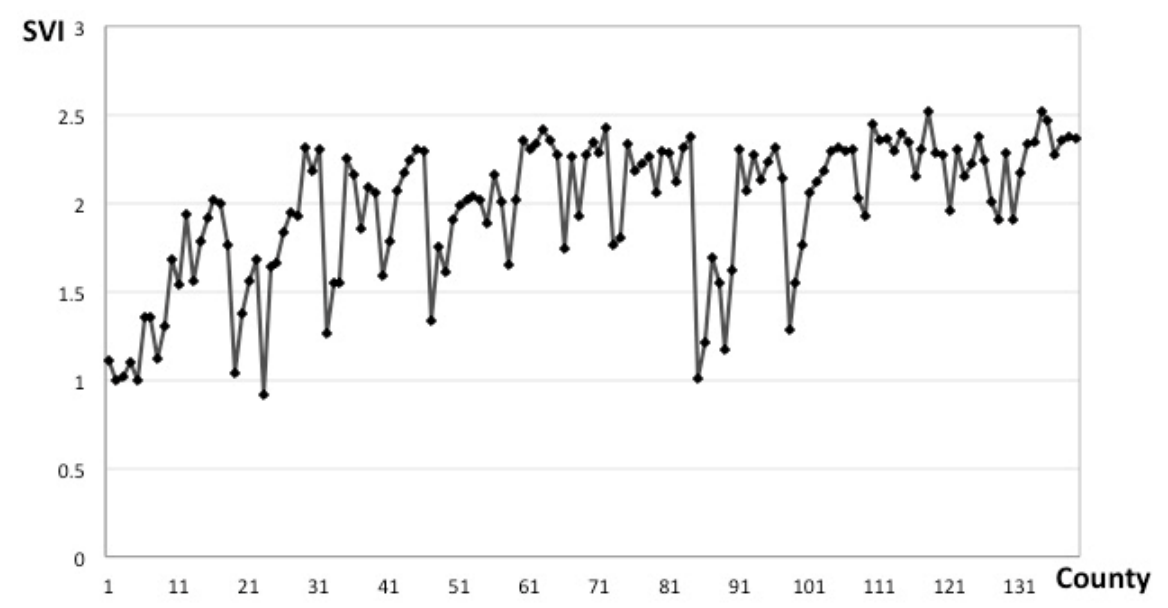

Figure 6. Changes of SVI values of all counties in the YRD region.

Table 4. General statistics of social vulnerability index in the YRD region.

\begin{tabular}{ccccc}
\hline SVI & YRD Region & Shanghai Municipality & Jiangsu Province & Zhejiang Province \\
\hline Average & 1.970 & 1.474 & 1.989 & 2.110 \\
Minimum & 0.916 & 0.992 & 0.916 & 1.002 \\
Maximum & 2.516 & 2.021 & 2.429 & 2.516 \\
\hline
\end{tabular}

In order to get further information of the spatial variability and distribution of SVI values, we mapped it with QGIS 2.14.10 (Quantum GIS Geographic Information System. Open Source Geospatial Foundation Project. http:/ / qgis.osgeo.org) (Figure 7). 


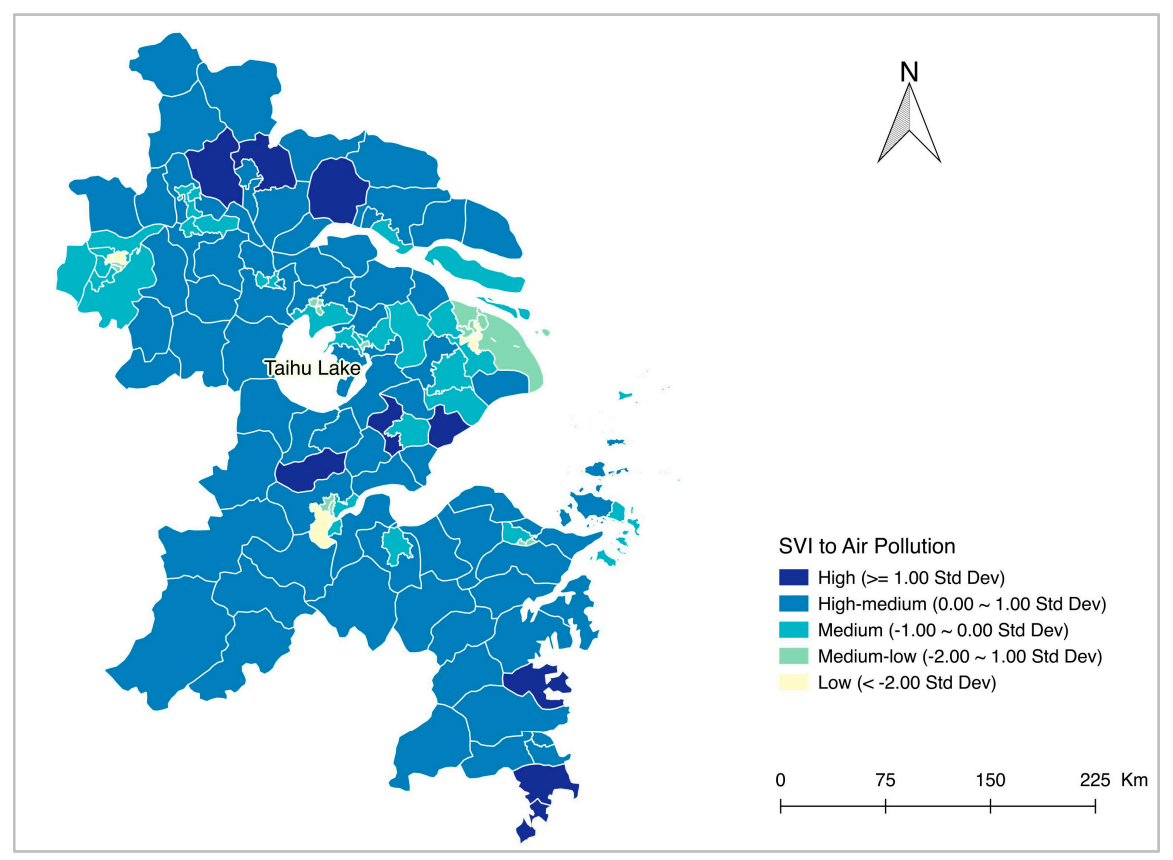

Figure 7. Spatial pattern of SVI at the county-level in the YRD region.

As expected, a spatial pattern of SVI at the county scale is clearly demonstrated. (1) High SVI values are mainly distributed in the north of Jiangsu Province, and the north and south of Zhejiang Province. It includes three county-level cities in Jiangsu Province: Qidong, Jiangdu and Jiangyan and one city district, two county-level cities, and three counties in Zhejiang Province: Xiuzhou, Pinghu, Deqing, Yuhuan, Sanmen, and Wenling; (2) As for the whole region, SVI is in generally poor condition, most of them are at level 4 (the high-medium level); (3) Examining SVI on the prefecture-level city scale, it can be found that the low value centers are always located in city districts. This means that urban core areas are always less vulnerable than surrounding counties or county-level cities. More detailed information is shown in Table 5.

Table 5. Statistics of SVI and SVI dimensions at the county-level in the YRD region.

\begin{tabular}{ccccccccc}
\hline \multirow{2}{*}{ Level } & \multicolumn{2}{c}{ SVI } & \multicolumn{2}{c}{ SVI Dimension 1 } & \multicolumn{2}{c}{ SVI Dimension 2 } & \multicolumn{2}{c}{ SVI Dimension 3 } \\
\cline { 3 - 8 } & \multicolumn{2}{c}{ Susceptibility } & \multicolumn{2}{c}{ Exposure } & \multicolumn{2}{c}{ Adaptability } \\
\cline { 2 - 8 } & Count & Percentage & Count & Percentage & Count & Percentage & Count & Percentage \\
\hline High & 9 & $6.47 \%$ & 7 & $5.04 \%$ & 11 & $7.91 \%$ & 54 & $38.85 \%$ \\
High-medium & 75 & $53.96 \%$ & 39 & $28.06 \%$ & 50 & $35.97 \%$ & 32 & $23.02 \%$ \\
Medium & 30 & $21.58 \%$ & 28 & $20.14 \%$ & 36 & $25.90 \%$ & 25 & $17.99 \%$ \\
Medium-low & 15 & $10.79 \%$ & 47 & $33.81 \%$ & 24 & $17.27 \%$ & 17 & $12.23 \%$ \\
Low & 10 & $7.20 \%$ & 18 & $12.95 \%$ & 18 & $12.95 \%$ & 11 & $7.91 \%$ \\
\hline
\end{tabular}

\section{Conclusions}

This article proposes a method for assessing social vulnerability to air pollution. First of all, we conceptualized social vulnerability in the context of air pollution after reviewing the literature on social vulnerability. Then, a range of factors concerned with social vulnerability to air pollution were identified and summarized, as well as developing a county-level dataset on a socioeconomic and demographic profile. With the PPC model, we identified the main factors contributing to social vulnerability in order to provide a benchmark reference for decision-makers on what social vulnerability reduction should be focused on. Results reveal that the top three factors influencing SVI are "educated", "physicians in hospital", and "employees in management sector". Based on the weight of each indicator, we evaluated the values of SVI dimensions (susceptibility, exposure, 
and adaptability) in the YRD region. It indicates that adaptability values are generally higher than susceptibility and exposure values. Hence, improving adaptability of this region will be an effective measure for reducing social vulnerability to air pollution. SVI values of all counties were also evaluated and mapped. As for the whole region, SVI is in a poor condition, because most values belong to level 4 (the high-medium level). SVI in Shanghai is better than Jiangsu and Zhejiang provinces. High SVI values are mainly distributed in the north of Jiangsu Province, and the north and south of Zhejiang Province. By examining SVI on the prefecture-level city scale, it can be found that the low value centers of SVI are always located in urban core areas. Hence, more attention should be paid on peripheral areas of the city than for prefecture-level management.

Acknowledgments: This study was financially supported by the National Natural Science Foundation of China (Grant No. 41571488 and Grant No. 41401382), Programme of Introducing Talents of Discipline to Universities (Grant No. B08008) and Office of Philosophical and Social Science of College and University in Jiangsu Province (Grant No. 2015SJD001). Thanks for the data support from "Lake-Watershed Science Data Center, National Earth System Science Data Sharing Infrastructure, National Science \& Technology Infrastructure of China". Special thanks to the reviewers and the editors for their critical comments that greatly helped in improving the quality of this article.

Author Contributions: Wen Dou conceived, designed and performed the computer code of PPC model; Yi Ge, Wen Dou and Haibo Zhang analyzed the data; Yi Ge, Haibo Zhang, Wenfang Chen, Ning Liu, Yuan Wang, Yulin Shi and Wenxin Rao contributed the materials; Yi Ge wrote the paper.

Conflicts of Interest: The authors declare no conflict of interest.

\section{References}

1. Lo, K. A critical review of China's rapidly developing renewable energy and energy efficiency policies. Renew. Sustain. Energy Rev. 2014, 29, 508-516. [CrossRef]

2. Yang, K.; Yang, Y.; Zhu, Y.; Li, C.; Meng, C. Social and economic drivers of $\mathrm{PM}_{2.5}$ and their spatial relationship in China. Geogr. Res. 2016, 35, 1051-1060. [CrossRef]

3. Zheng, S.; Yi, H.; Li, H. The impacts of provincial energy and environmental policies on air pollution control in China. Renew. Sustain. Energy Rev. 2015, 49, 386-394. [CrossRef]

4. Zou, B.; Pu, Q.; Luo, Y.; Tian, Y.; Zhang, W. On the complex indicative system based on the spatially divided urban areas for $\mathrm{PM}_{2.5}$ pollution \& control. J. Saf. Environ. 2016, 16, 337-342.

5. Kan, H. Environment and health in China: Challenges and opportunities. Environ. Health Perspect. 2009, 117, A530-A531. [CrossRef] [PubMed]

6. Lin, H.; Liu, T.; Xiao, J.; Zeng, W.; Li, X.; Guo, L.; Xu, Y.; Zhang, Y.; Vaughn, M.G.; Nelson, E.J.; et al. Quantifying short-term and long-term health benefits of attaining ambient fine particulate pollution standards in Guangzhou, China. Atmos. Environ. 2016, 137, 38-44. [CrossRef]

7. Fujii, H.; Managi, S.; Kaneko, S. Decomposition analysis of air pollution abatement in China: Empirical study for ten industrial sectors from 1998 to 2009. J. Clean. Prod. 2013, 59, 22-31. [CrossRef]

8. Wang, P.; Wang, G. PM 2.5 Pollution in China and its harmfulness to human health. Sci. Technol. Rev. 2014, 32, 72-78.

9. Chen, X.; Shao, S.; Tian, Z.; Xie, Z.; Yin, P. Impacts of air pollution and its spatial spillover effect on public health based on China's big data sample. J. Clean. Prod. 2017, 142, 915-925. [CrossRef]

10. Li, L.; Lin, G.Z.; Liu, H.Z.; Guo, Y.; Ou, C.Q.; Chen, P.Y. Can the Air Pollution Index be used to communicate the health risks of air pollution? Environ. Pollut. 2015, 205, 153-160. [CrossRef] [PubMed]

11. Feretis, E.; Theodorakopoulos, P.; Varotsos, C.; Efstathiou, M.; Tzanis, C.; Xirou, T.; Alexandridou, N.; Aggelou, M. On the plausible association between environmental conditions and human eye damage. Environ. Sci. Pollut. Res. 2002, 9, 163-165. [CrossRef]

12. Ferm, M.; Watt, J.; O'Hanlon, S.; De Santis, F.; Varotsos, C. Deposition measurement of particulate matter in connection with corrosion studies. Anal. Bioanal. Chem. 2006, 384, 1320-1330. [CrossRef] [PubMed]

13. Ferm, M.; de Santis, F.; Varotsos, C. Nitric acid measurements in connection with corrosion studies. Atmos. Environ. 2005, 39, 6664-6672. [CrossRef]

14. Ziemke, J.R.; Chandra, S.; Herman, J.; Varotsos, C. Erythemally weighted UV trends over northern latitudes derived from Nimbus 7 TOMS measurements. J. Geophys. Res. 2000, 105, 7373. [CrossRef] 
15. Katsambas, A.; Varotsos, C.A.; Veziryianni, G.; Antoniou, C. Surface solar ultraviolet radiation: A theoretical approach of the SUVR reaching the ground in Athens, Greece. Environ. Sci. Pollut. Res. Int. 1997, 4, 69-73. [CrossRef] [PubMed]

16. Hizbaron, D.R.; Baiquni, M.; Sartohadi, J.; Rijanta, R. Urban vulnerability in Bantul District, Indonesia-Towards safer and sustainable development. Sustainability 2012, 4, 2022-2037. [CrossRef]

17. Zhang, Y.; Shen, J.; Ding, F.; Li, Y.; He, L. Vulnerability assessment of atmospheric environment driven by human impacts. Sci. Total Environ. 2016, 571, 778-790. [CrossRef] [PubMed]

18. Pincetl, S.; Chester, M.; Eisenman, D. Urban heat stress vulnerability in the U.S. Southwest: The role of sociotechnical systems. Sustainability 2016, 8, 842. [CrossRef]

19. Nguyen, L.D.; Raabe, K.; Grote, U. Rural-Urban migration, household vulnerability, and welfare in Vietnam. World Dev. 2015, 71, 79-93. [CrossRef]

20. Wisner, B.; Blaikie, P.; Cannon, T.; Davis, I. At Risk: Natural Hazards, People's Vulnerability, and Disasters, 2nd ed.; Routledge: London, UK, 2004.

21. Willis, I. A brief Note Defining Vulnerability and Risk. Available online: https://iainwillis.wordpress.com/ 2012/01/18/a-brief-note-defining-vulnerability-and-risk/ (accessed on 20 June 2011).

22. Fussel, H.-M. Vulnerability: A generally applicable conceptual framework for climate change research. Glob. Environ. Chang. 2007, 17, 155-167. [CrossRef]

23. Li, X.; Zhou, Y.; Tian, B.; Kuang, R.; Wang, L. GIS-based methodology for erosion risk assessment of the muddy coast in the Yangtze Delta. Ocean Coast. Manag. 2015, 108, 97-108. [CrossRef]

24. Janssen, M.A.; Schoon, M.L.; Ke, W.; Bo, K. Scholarly networks on resilience, vulnerability and adaptation within the human dimensions of global environmental change. Glob. Environ. Chang. 2006, 16, 240-252. [CrossRef]

25. Zhou, Y.; Li, N.; Wu, W.; Wu, J.; Shi, P. Local spatial and temporal factors influencing population and societal vulnerability to natural disasters. Risk Anal. 2014, 34, 614-639. [CrossRef] [PubMed]

26. Dow, K. Exploring differences in our common future(s): The meaning of vulnerability to global environmental change. Geoforum 1992, 23, 417-436. [CrossRef]

27. Cutter, S.L. Vulnerability to environmental hazards. Prog. Hum. Geogr. 1996, 20, 529-539. [CrossRef]

28. Birkmann, J. Measuring vulnerability to promote disaster-resilient societies: Conceptual frameworks and definitions. In Measuring Vulnerability to Natural Harzards: Towards Disaster Resilient Societies; United Nations University Press: New York, NY, USA, 2006; pp. 9-54.

29. Cutter, S.L.; Carolina, S.; Boruff, B.J.; Shirley, W.L.; Carolina, S.; Shirley, W.L.; Carolina, S. Social vulnerability to environmental hazards. Soc. Sci. Q. 2003, 84, 242-261. [CrossRef]

30. Ge, Y.; Liu, J.; Li, F.; Shi, P. Quantifying social vulnerability for flood disasters of insurance company. J. Southeast Univ. 2008, 24, 147-150.

31. Neil, L.; Conde, C.; Kulkarni, J.; Nyong, A.; Pulbin, J. Climate Change and Vulnerability; Earthscan: London, UK; Sterling, VA, USA, 2008.

32. Blaikie, P.; Cannon, T.; Davis, I.; Wisner, B. At Risk: Natural Hazards, People's Vulnerability, and Disasters; Routledge: London, UK, 1994.

33. Turner, B.L., II; Kasperson, R.E.; Matson, P.A.; Mccarthy, J.J.; Corell, R.W.; Christensen, L.; Eckley, N.; Kasperson, J.X.; Luers, A.; Martello, M.L.; et al. A framework for vulnerability analysis in sustainability science. PNAS 2003, 100, 14. [CrossRef] [PubMed]

34. Chen, W.; Cutter, S.L.; Emrich, C.T.; Shi, P. Measuring social vulnerability to natural hazards in the Yangtze River Delta region, China. Int. J. Disaster Risk Sci. 2013, 4, 169-181. [CrossRef]

35. Dwyer, A.; Zoppou, C.; Nielsen, O.; Day, S.; Roberts, S. Quantifying Social Vulnerability: A Methodology for Identifying Those at Risk to Natural Hazards; Geoscience Australia: Canberra, Australia, 2004.

36. Ge, Y.; Dou, W.; Gu, Z.; Qian, X. Assessment of social vulnerability to natural hazards in the Yangtze River Delta, China. Stoch. Environ. Res. Risk Assess. 2013, 27, 1899-1908. [CrossRef]

37. New Indicators of Vulnerability and Adaptive Capacity. Available online: http://www.tyndall.ac.uk/ content/new-indicators-vulnerability-and-adaptive-capacity (accessed on 11 January 2017).

38. Wood, N.J.; Burton, C.G.; Cutter, S.L. Community variations in social vulnerability to Cascadia-related tsunamis in the U.S. Pacific Northwest. Nat. Hazards 2010, 52, 369-389. [CrossRef]

39. Holand, I.S.; Lujala, P. Replicating and adapting an index of social vulnerability to a new context: A comparison study for Norway. Prof. Geogr. 2013, 65, 312-328. [CrossRef] 
40. Zhou, Y.; Li, N.; Wu, W.; Wu, J. Assessment of provincial social vulnerability to natural disasters in China. Nat. Hazards 2014, 71, 2165-2186. [CrossRef]

41. Cutter, S.L.; Finch, C. Temporal and spatial changes in social vulnerability to natural hazards. Proc. Natl. Acad. Sci. USA 2008, 7, 2301-2306. [CrossRef] [PubMed]

42. Tierney, K. Social inequality, hazards, and disasters. In On Risk and Disaster: Lessons from Hurricane Katrina; Daniels, R.J., Kettl, E.F., Kunreuther, H., Eds.; University of Pennsylvania Press: Philadephia, PA, USA, 2006; pp. 109-128.

43. Wei, Y.M.; Fan, Y.; Lu, C.; Tsai, H.T. The assessment of vulnerability to natural disasters in China by using the DEA method. Environ. Impact Assess. Rev. 2004, 24, 427-439. [CrossRef]

44. Huang, J.; Liu, Y.; Ma, L. Assessment of regional vulnerability to natural hazards in China using a DEA model. Int. J. Disaster Risk Sci. 2011, 2, 41-48. [CrossRef]

45. Fan, Y.; Luo, Y.; Chen, Q. Establishment of weight about vulnerability indexes of a hazard bearing body. J. Catastr. 2001, 16, 85-87.

46. Roy, D.C.; Blaschke, T. Spatial vulnerability assessment of floods in the coastal regions of Bangladesh. Geomat. Nat. Hazards Risk 2013, 5705, 1-24. [CrossRef]

47. Rygel, L.; O'Sullivan, D.; Yarnal, B. A method for constructing a social vulnerability index: An application to hurricane storm surges in a developed country. Mitig. Adapt. Strateg. Glob. Chang. 2006, 11, 741-764. [CrossRef]

48. Frigerio, I.; de Amicis, M. Mapping social vulnerability to natural hazards in Italy: A suitable tool for risk mitigation strategies. Environ. Sci. Policy 2016, 63, 187-196. [CrossRef]

49. Frigerio, I.; Ventura, S.; Strigaro, D.; Mattavelli, M.; de Amicis, M.; Mugnano, S.; Bof, M. A GIS-based approach to identify the spatial variability of social vulnerability to seismic hazard in Italy. Appl. Geogr. 2016, 74, 12-22. [CrossRef]

50. Carpiano, R.M.; Link, B.G.; Phelan, J.C. Social Inequality and Health: Future direction for the fundamental cause explanation. In Social Class: How Does It Works? Russell Sage Foundation: New York, NY, USA, 2008; pp. 232-263.

51. Makri, A.; Stilianakis, N.I. Vulnerability to air pollution health effects. Int. J. Hyg. Environ. Health 2008, 211, 326-336. [CrossRef] [PubMed]

52. Jain, S.; Khare, M. Urban air quality in mega cities: A case study of Delhi City using vulnerability analysis. Environ. Monit Assess 2008, 136, 257-265. [CrossRef] [PubMed]

53. Flanagan, B.E.; Gregory, E.W.; Hallisey, E.J.; Heitgerd, J.L.; Lewis, B. A social vulnerability index for disaster management. J. Homel. Secur. Emerg. Manag. 2011, 8, 1-22. [CrossRef]

54. Bentayeb, M.; Simoni, M.; Baiz, N.; Norback, D.; Baldacci, S.; Maio, S.; Viegi, G.; Annesi-Maesano, I. Adverse respiratory effects of outdoor air pollution in the elderly. Int. J. Tuberc. Lung Dis. 2012, 16, 1149-1161. [CrossRef] [PubMed]

55. Simoni, M.; Baldacci, S.; Maio, S.; Cerrai, S.; Sarno, G.; Viegi, G. Adverse effects of outdoor pollution in the elderly. J. Thorac. Dis. 2015, 7, 34-45.

56. World Health Organization (WHO). Effects of Air Pollution on Children's Health and Development a Review of the Evidence Special Programme on Health and Environment; WHO: Copenhagen, Denmark, 2005.

57. Morrow, B.H. Identifying and mapping community vulnerability. Disasters 1999, 23, 1-18. [CrossRef] [PubMed]

58. Holand, I.S.; Lujala, P.; Rød, J.K. Social vulnerability assessment for Norway: A quantitative approach. Nor. Geogr. Tidsskr.-Nor. J. Geogr. 2011, 65, 1-17. [CrossRef]

59. Wang, Q. Vulnerability analysis of cities to $\mathrm{PM}_{2.5}$. Mod. Bus. Trade Ind. 2014, 59-61.

60. Finkelstein, M.M.; Jerrett, M.; Sears, M.R. Environmental inequality and circulatory disease mortality gradients. J. Epidemiol. Community Health 2005, 59, 481-487. [CrossRef] [PubMed]

61. Finkelstein, M.M.; Jerrett, M.; DeLuca, P.; Finkelstein, N.; Verma, D.K.; Chapman, K.; Sears, M.R. Relation between income, air pollution and mortality: A cohort study. Can. Med. Assoc. J. 2003, 169, 397-402.

62. Jerrett, M.; Burnett, R.T.; Brook, J.; Kanaroglou, P.; Giovis, C.; Finkelstein, N.; Hutchison, B. Do socioeconomic characteristics modify the short term association between air pollution and mortality? Evidence from a zonal time series in Hamilton, Canada. J. Epidemiol. Community Health 2004, 58, 31-40. [CrossRef] [PubMed] 
63. Wheeler, B.W.; Ben-Shlomo, Y. Environmental equity, air quality, socioeconomic status, and respiratory health: A linkage analysis of routine data from the health survey for England. J. Epidemiol. Community Health 2005, 59, 948-954. [CrossRef] [PubMed]

64. Gunier, R.B.; Hertz, A.; von Behren, J.; Reynolds, P. Traffic density in California: Socioeconomic and ethnic differences among potentially exposed children. J. Expo. Anal. Environ. Epidemiol. 2003, 13, 240-246. [CrossRef] [PubMed]

65. Mildrexler, D.; Yang, Z.; Cohen, W.B.; Bell, D.M. A forest vulnerability index based on drought and high temperatures. Remote Sens. Environ. 2015, 173, 314-325. [CrossRef]

66. Filleul, L.; Rondeau, V.; Cantagrel, A.; Dartigues, J.-F.; Tessier, J.-F. Do subject characteristics modify the effects of particulate air pollution on daily mortality among the elderly? J. Occup. Environ. Med. 2004, 46, 1115-1122. [CrossRef] [PubMed]

67. Wang, T.; Jiang, F.; Deng, J.; Shen, Y.; Fu, Q.; Wang, Q.; Fu, Y.; Xu, J.; Zhang, D. Urban air quality and regional haze weather forecast for Yangtze River Delta region. Atmos. Environ. 2012, 58, 70-83. [CrossRef]

68. Li, L.; Chen, C.H.; Fu, J.S.; Huang, C.; Streets, D.G.; Huang, H.Y.; Zhang, G.F.; Wang, Y.J.; Jang, C.J.; Wang, H.L.; et al. Air quality and emissions in the Yangtze River Delta, China. Atmos. Chem. Phys. 2011, 11, 1621-1639. [CrossRef]

69. Sarkar, A.; Vulimiri, A.; Bose, S.; Paul, S.; Ray, S.S. Unsupervised hyperspectral image analysis with projection pursuit and MRF segmentation approach. In Proceedings of the International Conference on Artificial Intelligence and Pattern Recognition 2008, AIPR 2008, Orlando, FL, USA, 7-10 July 2008.

70. Nason, G.P. Robust projection indices. J. R. Stat. Soc. Ser. B 2001, 63, 551-567. [CrossRef]

(C) 2017 by the authors; licensee MDPI, Basel, Switzerland. This article is an open access article distributed under the terms and conditions of the Creative Commons Attribution (CC-BY) license (http:/ / creativecommons.org/licenses/by/4.0/). 